\title{
NASA-ESA TRANS-ATLANTIC TRAINING (TAT) 2013-2015
}

\author{
Štych P. ${ }^{1}$, Mouratidis A. ${ }^{1,2,3}$, Sarti F. ${ }^{3}$ and Gutman G. ${ }^{4}$ \\ ${ }^{I}$ Charles University in Prague, Department of Applied Geoinformatics and Cartography, Albertov \\ 6, 12843 Prague 2, Czech Republic, stych@natur.cuni.cz, antonios.mouratidis.esa.int@gmail.com \\ ${ }^{2}$ Aristotle University of Thessaloniki, School of Geology, 54124, Thessaloniki, Greece, \\ amourati@geo.auth.gr \\ ${ }^{3}$ European Space Agency (ESA), ESA/ESRIN, Via Galileo Galilei, 00044, Frascati, Italy, \\ francesco.sarti@esa.int, antonios.mouratidis.esa.int@gmail.com
}

${ }^{4}$ National Aeronautics and Space Administration (NASA), NASA Headquarters, 300 E Street, SW Washington, DC 20546, USA, ggutman@ nasa.gov

\begin{abstract}
Since 2013, NASA and ESA, in cooperation with Charles University in Prague (Czech Republic), have been joining forces and sharing expertise within the organization of annual Trans-Atlantic-Training (TAT) events in Eastern European countries. TAT concerns capacity building on Earth Observation from Space and focuses mainly on land cover/land use applications. With three TATs already organized between 2013 and 2015, the purpose of this paper is to provide an overview of the context and achievements so far, to increase the visibility of these events to larger audiences in Eastern Europe and to discuss the future prospects. To this end, some background information is initially provided, with subsequent description of each TAT event, concerning its organization, thematic content and participants. The paper concludes with an overall assessment and a vision for the future of TAT, including its enlargement with the engagement of participants from more countries.

Keywords: Education, Capacity Building, Earth Observation from Space, Eastern Europe.

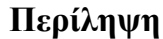

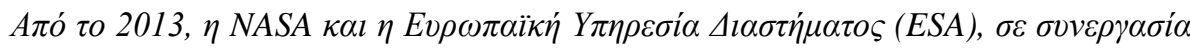

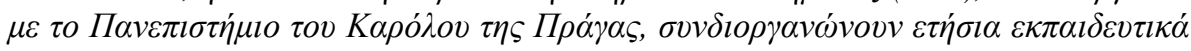

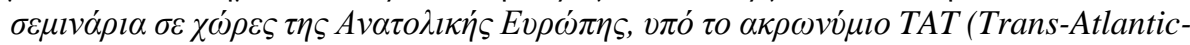

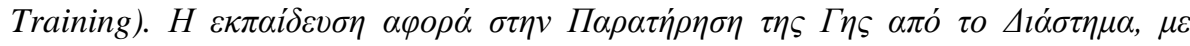

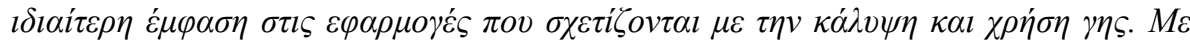

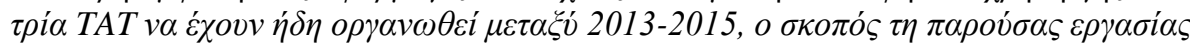

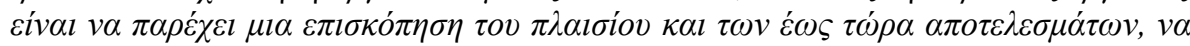

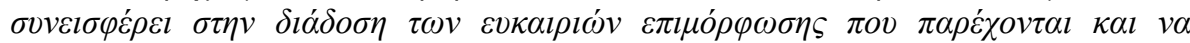

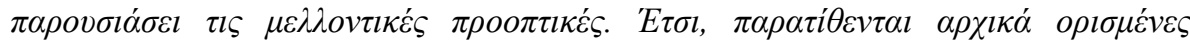

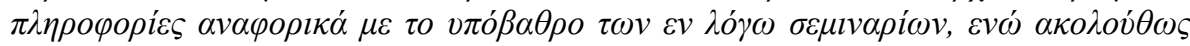

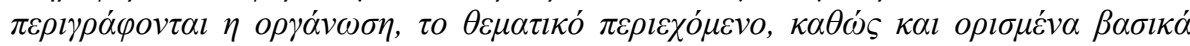

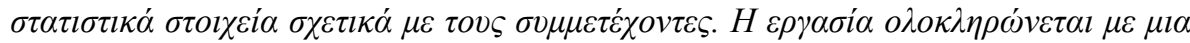

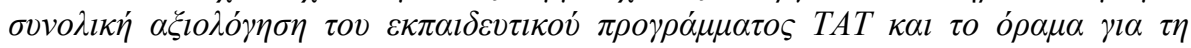

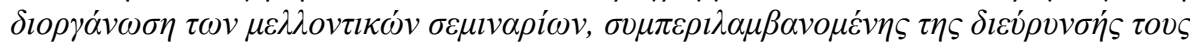

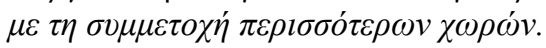




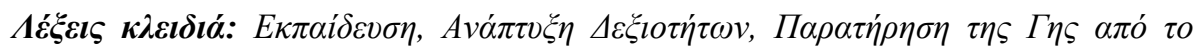

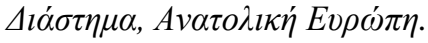

\section{Introduction}

Earth Observation (EO) from Space is a rapidly growing field in the broader domain of geospatial technology. Every year, Space Agencies around the world launch new satellites, which carry sophisticated sensors and advanced instruments for mapping and monitoring the Earth's environment. Apart from the plethora of applications and the established scientific interest, EO is nowadays also highly operational, with several initiatives focusing on issues like (natural) disasters monitoring and security.

Education, training, capacity building and outreach activities are thus of paramount importance, to the end of introducing, demonstrating and ultimately attracting the interest of next generations of scientists, engineers and decision-makers to the utilization of EO technology. As the field of EO is very broad, dedicated training sessions per thematic area and/or per target group are necessary, for the essence of "capacity building" to be achieved.

In this context, since 2013, the National Aeronautics and Space Administration (NASA), the European Space Agency (ESA) and Charles University in Prague, Czech Republic, have been cooperating for the organization of a series of annual workshops and training courses in EO techniques and applications. These "Trans-Atlantic Training (TAT)" events are geographically focused on Eastern Europe, while the thematic emphasis is on the mapping and monitoring of Land Use/Land Cover (LU/LC) from Space. The duration of a TAT is typically between three to five days. TAT teachers are typically principal investigators from Europe (sponsored by ESA) and EO experts from the US (invited by NASA). The target audience is primarily university students, scientists, engineers, young professionals and early-stage researchers from Eastern European countries that wish to expand their knowledge in the field. TAT also serves networking purposes, by fostering and promoting the cooperation among participants (experts and students).

As three TAT events have been organized to date, the purpose of this paper is to summarize the progress so far, to evaluate the impact and to promote TAT to a larger audience, in view of the organization of future TATs.

\section{Background}

Several Eastern European countries are already full ESA Member States; The Czech Republic formally became ESA's 18th Member State on 12 November 2008. Romania became ESA's 19th Member State on 22 December 2011, and Poland exchanged Accession Agreements with ESA in September 2012. The latest to join are Estonia, which signed the Accession to the ESA Convention on 4 February 2015, to become the $21^{\text {st }}$ Member State, and Hungary, which signed on 24 February 2015 , to become the $22^{\text {nd }}$ Member State.

Other EU States also have Cooperation Agreements with ESA, such as Bulgaria, Cyprus, Lithuania and Malta. Latvia, Slovenia and Slovakia are participating in the Plan for European Cooperating States (http://www.esa.int/About_Us/Welcome_to_ESA/European_Cooperating_States).

In this context, ESA's intention has been to further support countries of Eastern Europe and Baltic countries by means of capacity building in Earth Observation and the co-organization, with NASA, of a series of related workshops and training courses has been decided in 2013 (Sarti and Mouratidis, 2013). Note that NASA has a long tradition in optical remote sensing for Earth Observation purposes, mainly with the launch of eight Landsat satellites since 1972 (Landsat Programme), while ESA has an established expertise in microwave remote sensing, with several successful spaceborne Synthetic Aperture Radar (SAR) missions since 1991 (ERS-1, ERS-2, Envisat/ASAR, Sentinel-1). Therefore, a joint ESA-NASA approach would bring the maximum benefit for the participating countries. 
In this context, the "Trans-Atlantic Training" (TAT) initiative was established in 2013, with the purpose of organizing joint capacity building events on Earth Observation in Eastern Europe. It has been agreed that the emphasis would be given to state-of-the-art remote sensing technology on land cover and land use change, presented by leading experts from Europe (funded by ESA) and US (funded by NASA). The training would include theory, as well as hands-on sessions and tutorials with the use of data from the latest ESA and NASA EO missions. As per their expertise, ESA would be responsible for the SAR training sessions, while NASA would cover the sessions related to optical remote sensing.

Priority would be given to candidates from Eastern Europe, with the selection procedure being jointly carried out by NASA, ESA and Charles University in Prague, on the basis of the applicants' background, qualifications, research interests, but also gender and geographical distribution, where possible. The courses would also be open to a limited number of participants from other countries, should they demonstrate their relevance to the topics addressed and if the maximum number of participants would not have been already reached. In order to allow an efficient running of the practical training sessions, the total number of participants would be around 35 to 40 as a maximum. ESA also agreed to provide a limited number of travel grants, covering part of the travel and accommodation expenses, to a restricted number of selected students from its Member or Cooperating States.

Charles University in Prague, Czech Republic has been selected to be responsible for the organization and local management of TAT events for several reasons; (1) its excellence and experience in the organisation of similar workshops and training events with ESA and other international partners, (2) its strategic geographical location in Eastern Europe and (3) the fact that Czech Republic is the oldest ESA Member State among the countries involved.

\section{Training Events}

\subsection{TAT 2013}

The first of the TAT capacity building events was held in Prague, Czech Republic, for three days during 20-22 June 2013 and it was hosted by the Faculty of Science, Charles University in Prague. The topic addressed was "Classification methods in Land-Use/Land-Cover Change".

TAT 2013 was organized in coordination with the first South Central and Eastern European Regional Information Network (SCERIN) Meeting (http://www.fao.org/gtos/gofc-gold/net-SEERIN.html), which took place in the same location during 17-21 June (http://csebr.cz/scerin2013/index.html). SCERIN is one of the regional networks of the Global Observation of Forest and Land Cover Dynamics (GOFC-GOLD) panel. GOFC-GOLD in its turn is a panel of the Global Terrestrial Observing System (GTOS) - a programme for observations, modelling, and analysis of terrestrial ecosystems to support sustainable development. SCERIN (originally SEERIN) is an informal network of scientists and other professionals based in the region or with scientific interests in the region of South Eastern and Central Europe, encompassing the Danube watershed and the western Black Sea Coast.

The primary purpose of combining the two events was to give TAT participants the additional opportunity to interact with SCERIN experts, benefiting from their experience and creating networks of cooperation.

TAT 2013 was attended by 22 participants from five countries (table 1) and included lectures and/or practicals (Figure 1) on:

1. Forest mapping

2. Assessment of ecosystem carbon

3. Multi-temporal land cover classification 
4. Land cover classifications and social studies

5. Spectroscopy for vegetation and geological analysis

6. Algorithms of hyperspectral classification

7. SAR for agriculture and wetland studies

8. Land applications using multi-temporal SAR data

9. SAR in urban land cover

10. Urban remote sensing and object-based image analysis (OBIA)

Table 1 - Participants of TAT 2013 per country of origin.

\begin{tabular}{|l|c|}
\hline \multicolumn{1}{|c|}{ Country } & $\begin{array}{c}\text { No. of } \\
\text { Participants }\end{array}$ \\
\hline Czech Republic & 12 \\
\hline Poland & 5 \\
\hline Slovakia & 3 \\
\hline Germany & 1 \\
\hline Hungary & 1 \\
\hline TOTAL & $\mathbf{2 2}$ \\
\hline
\end{tabular}

\subsection{TAT 2014}

TAT 2014 entitled "Land Use/Land Cover Change and Ecosystem Processes" was held in Krakow, Poland, from 5 to 7 June 2014. The course was hosted by the Institute of Geography and Spatial Management, Jagiellonian University.

Once again TAT was jointly organized with the annual SCERIN Meeting. This second (SCERIN2) meeting had a focus on "Current Land Cover/Land Use Change challenges in SCERIN: Assessing Ecosystem Function and Processes" and took place during 9-10 June.

A total of 36 participants from 12 countries (Table 2) took part in TAT 2014, while lectures and practical training was delivered on the following topics:

1. Potential and limitations of global land monitoring from space

2. SAR missions and applications

3. Introduction to SAR basics

4. Introduction to basic SAR processing using NEST

5. Introduction to SAR applications for Forestry

6. Satellite SAR data in land cover mapping and forestry applications

7. Land cover change detection

8. Multi-temporal land-cover classification of pixel-based composites

9. Land surface phenology

10. LiDAR

11. Effect of climatic changes on grassland growth, its water conditions and biomass 


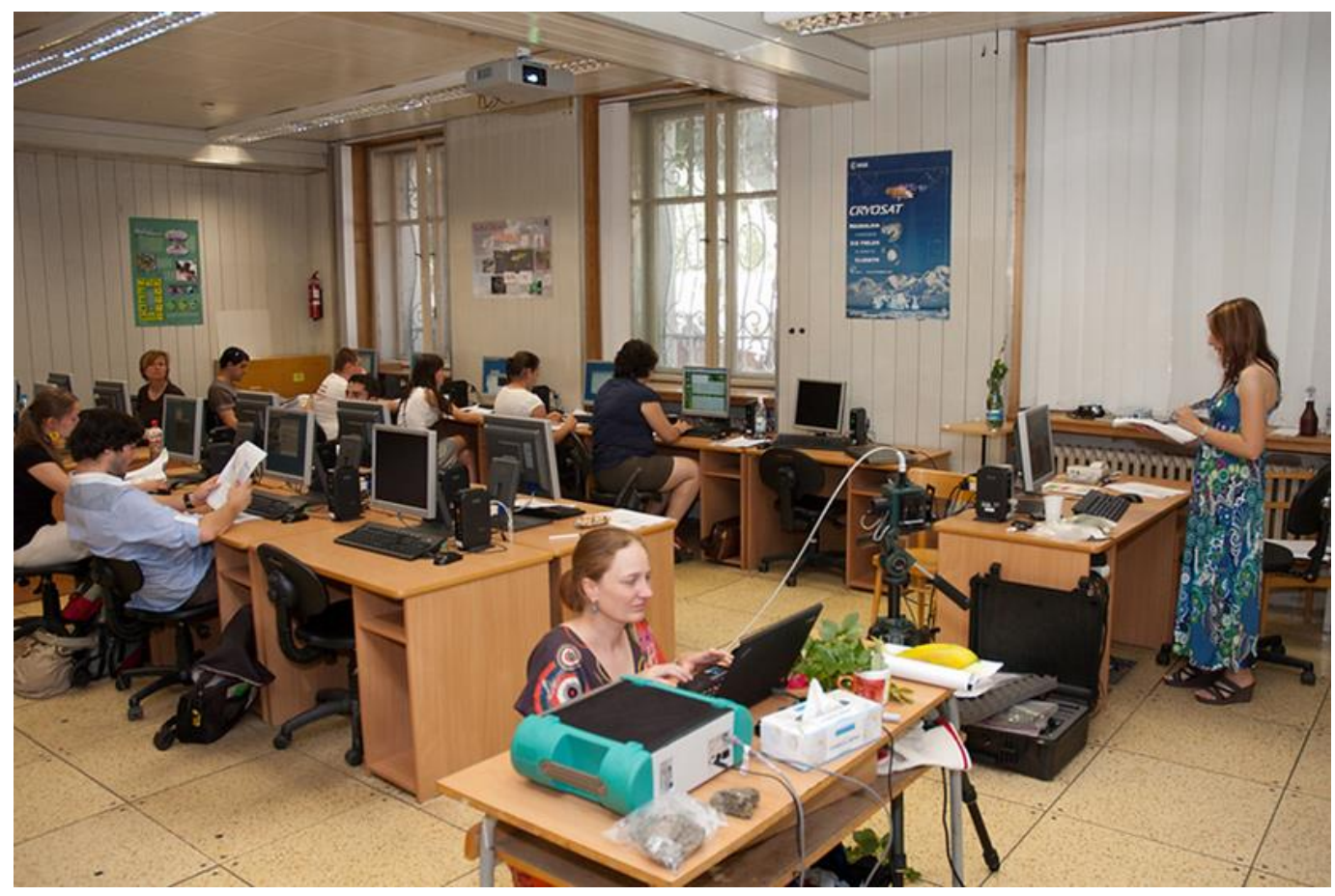

Figure 1 - TAT 2013 hands-on session and spectroscopy experiments.

Thematic presentations and discussions focused on Land Use/Land Cover Change and ecosystems processes. The state-of-the-art advanced methods of land-cover change evaluation were presented and discussed by leading experts from Europe and US. Impact of land use cover change on ecosystems, such as forest disturbance, urban sprawl, and land abandonment were addressed. Additionally, the compatibility and accuracy of the related main databases, such as Corine Land Cover (CLC), GlobCover, National Land Cover Database (NLCD) and Global Land Cover Characterization (GLCC) were discussed. Emphasis was also given to the use of data from Landsat8 and Sentinel missions.

Table 2 - Participants of TAT 2014 per country of origin.

\begin{tabular}{|l|c|}
\hline \multicolumn{1}{|c|}{ Country } & $\begin{array}{c}\text { No. of } \\
\text { Participants }\end{array}$ \\
\hline Poland & 11 \\
\hline Czech Republic & 7 \\
\hline Estonia & 4 \\
\hline Hungary & 4 \\
\hline Slovakia & 3 \\
\hline Bulgaria & 1 \\
\hline Germany & 1 \\
\hline Greece & 1 \\
\hline Lithuania & 1 \\
\hline Moldova & 1 \\
\hline Spain & 1 \\
\hline The Netherlands & 1 \\
\hline TOTAL & $\mathbf{3 6}$ \\
\hline
\end{tabular}




\subsection{TAT 2015}

TAT 2015 was organized by Charles University in Prague, Czech Republic during 8-12 April 2015, with participation from 9 countries and 29 participants in total (table 3). Under the general training course title "Earth Observation in Terrestrial Ecosystem Dynamics", the following topics were covered with theory and hands-on sessions (Figure 2):

1. Observing Ecosystem Dynamics: NASA Update

2. Introduction to ESA SAR missions

3. Hyperspectral data for the mapping of mountain vegetation

4. Object-based land cover classification using very high resolution data

5. Advanced methods of land cover change detection

6. Phenological studies based on remote sensing data

7. Permafrost and snowmelt monitoring with satellite data

8. SAR land applications

9. Flood mapping with SAR

10. Synergies of EO data with Geographical Information Systems (GIS) and Global Navigation Satellite Systems (GNSS)

11. Additionally, for one day, TAT 2015 students had the opportunity to follow the Northern Eurasia Earth Science Partnership Initiative (NEESPI, http://neespi.org/) Meeting, which was taking place at Charles University in Prague, during the same week.

12. NEESPI, is an active and strategically evolving program of internationally-supported Earth systems science research, which focuses on issues of northern Eurasia that are relevant to regional and global scientific and decision-making communities. NEESPI aims at operating synergistically with a variety of national and international science programs (particularly those relevant to global change research) and to develop enhanced knowledge on the northern Eurasia region. It is envisaged that this knowledge shall be applied for the purposes of addressing specific concerns, which are faced by national and international decision-makers of the partnering institutions and countries. 


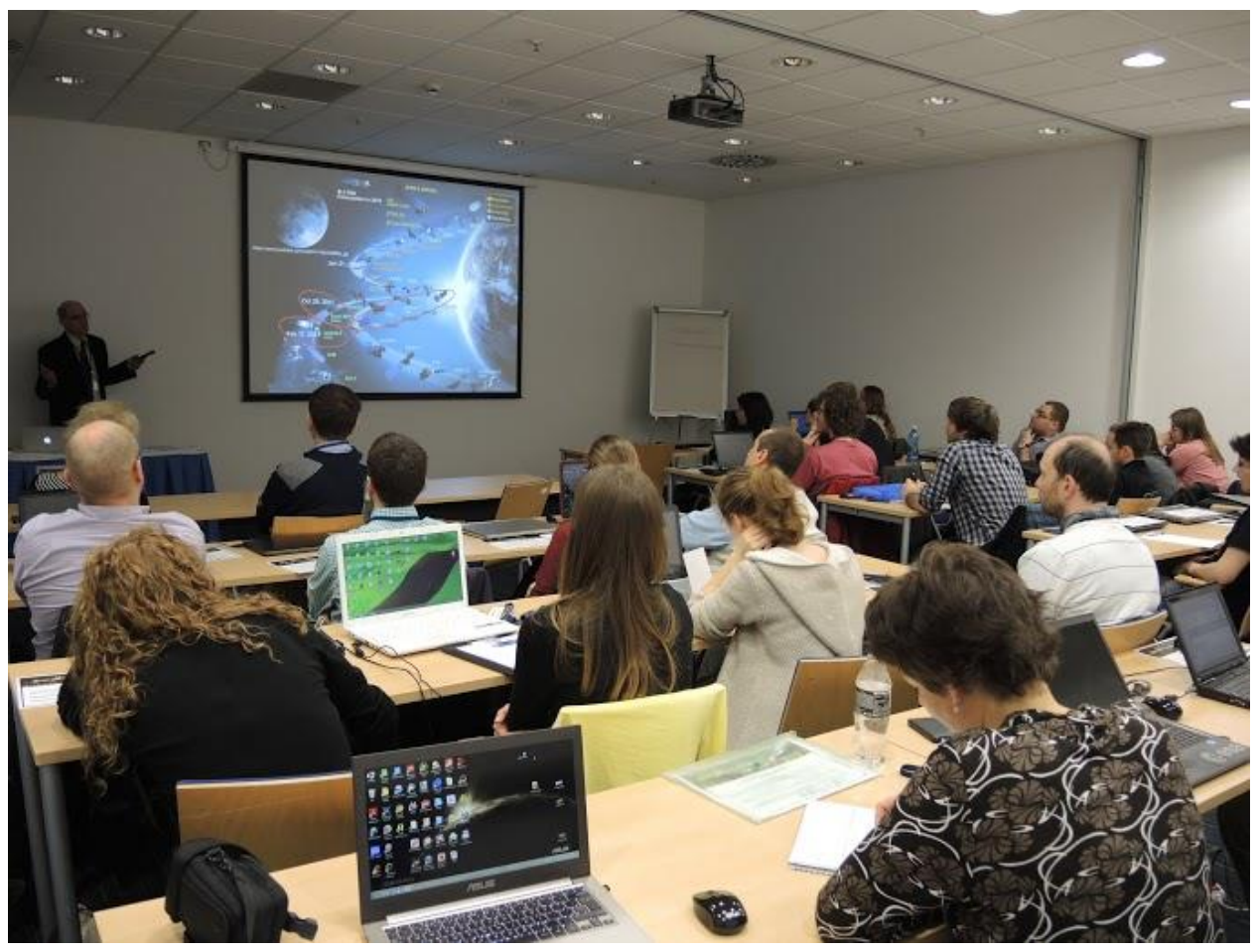

Figure 3 - Introductory NASA lecture on the observation of ecosystem dynamics during TAT 2015.

Table 3 - Participants of TAT 2015 per country of origin.

\begin{tabular}{|l|c|}
\hline \multicolumn{1}{|c|}{ Country } & $\begin{array}{c}\text { No. of } \\
\text { Participants }\end{array}$ \\
\hline Czech Republic & 10 \\
\hline Poland & 8 \\
\hline Hungary & 3 \\
\hline Germany & 2 \\
\hline Slovakia & 2 \\
\hline Armenia & 1 \\
\hline Brazil & 1 \\
\hline Estonia & 1 \\
\hline Spain & 1 \\
\hline TOTAL & $\mathbf{2 9}$ \\
\hline
\end{tabular}

\section{Overall Assessment of TAT 2013-2015}

TAT has been received with great interest and has been supported by universities and other research institutes in Eastern Europe, both in terms of student applications, as well as in the form of experts willing to teach during the capacity building events. Charles University in Prague (twice) and the Jagiellonian University of Krakow have been the two hosts of TAT events so far. 
A total of 87 students attended the first three TAT events, i.e. about 30 participants per year, with a very balanced distribution between male (47\%) and female (53\%) participants (table 4).

A limited participation from other countries, such as Spain, Greece and Germany was also made possible in some cases. In terms of nationalities represented, on top of those of the countries already mentioned in tables 1-3, there have been also Georgian, Indian, Nepalese and Brazilian participants - thus reaching a total of 13 different nationalities.

The coupling of TAT with other relevant events such as SCERIN (2013 and 2014) and NEESPI (2015) has been a strong element of the TAT initiative, as it has fostered a more extended interaction of experts and students beyond the TAT training sessions.

Table 4 - Ensemble statistics of TAT 2013-2015.

\begin{tabular}{|c|c|c|c|}
\hline \multirow{2}{*}{ Training Event } & No. of Participants & \multicolumn{2}{|c|}{ Gender } \\
\cline { 3 - 4 } & 22 & 10 & Male \\
\hline TAT 2013 & 36 & 19 & 17 \\
\hline TAT 2014 & 29 & 12 & 17 \\
\hline TAT 2015 & $\mathbf{8 7}$ & $\mathbf{4 1}$ & $\mathbf{4 6}$ \\
\hline TOTAL & & & \\
\hline
\end{tabular}

\section{Conclusions and Future Prospects}

In its three years of lifetime, TAT has become a point of reference and a meeting opportunity for several young researchers and students in Eastern Europe, in order to share ideas and progress made in their fields of interest, but also to meet and interact with leading experts from Europe and the US. The joint presence of NASA and ESA have ensured that state-of-the-art advances in EO have been presented on an annual basis and guaranteed the overall high quality of the training provided.

As per the future prospects, continuing and enlarging TAT by engaging participants from more countries would be considered as a realistic goal. This could be achieved by attracting participants from other countries that can benefit from an initiative such as TAT. This includes countries of South/South-Eastern Europe and the Balkans, such as Greece (ESA Member State since 2005) and near-future ESA Member States such as Malta, Cyprus and Bulgaria.

The next TAT capacity building events could be organised with a rotation mechanism in different countries in the region, in order to facilitate the diversity of participation and to foster cooperation at regional level between the attendees. In this respect, the next TAT event is planned to be held in Slovakia in July 2016.

\section{Acknowledgments}

EO experts from Europe and the U.S. are gratefully acknowledged for their willingness and enthusiasm to teach and share their expertise and experience with TAT students. Special thanks are also due to the TAT local organizing committee members of Charles University in Prague (Czech Republic) and Jagiellonian University of Krakow (Poland), for all their efforts and altruistic support. Last but not least, the TAT participants are to be thanked for their interest and active participation during the first three training events, which has significantly contributed to its overall success and encouraged for the organization of more TATs in the future. 


\section{References}

Sarti, F. and Mouratidis, A., 2013. Earth Observation Capacity Building for Baltic Countries and Eastern Europe, Statement of Work, Issue 4, Ref. EOP-SA/0246/FS-fs, ESA/ESRIN, 28 May 2013.

\section{Internet sources}

ESA European Cooperating States:

http://www.esa.int/About_Us/Welcome_to_ESA/European_Cooperating_States

Global Observation of Forest and Land Cover Dynamics (GOFC-GOLD): http://www.fao.org/gtos/gofc-gold/index.html

Global Terrestrial Observing System (GTOS): http://www.fao.org/gtos

Northern Eurasia Earth Science Partnership Initiative (NEESPI): http://neespi.org

South Central and Eastern European Regional Information Network (SCERIN): http://www.fao.org/gtos/gofc-gold/net-SEERIN.html

Trans-Atlantic Training (TAT): http://web.natur.cuni.cz/gis/tat 